Canadian University Music Review

Revue de musique des universités canadiennes

\title{
A Shakespeare Music Catalogue: "What's in a Name?"
}

\section{Bryan N. S. Gooch}

Numéro 7, 1986

URI : https://id.erudit.org/iderudit/1014090ar

DOI : https://doi.org/10.7202/1014090ar

Aller au sommaire du numéro

\section{Éditeur(s)}

Canadian University Music Society / Société de musique des universités

canadiennes

\section{ISSN}

0710-0353 (imprimé)

2291-2436 (numérique)

Découvrir la revue

\section{Citer cet article}

Gooch, B. N. S. (1986). A Shakespeare Music Catalogue: "What's in a Name?". Canadian University Music Review / Revue de musique des universités

canadiennes, (7), 127-140. https://doi.org/10.7202/1014090ar

All Rights Reserved (C Canadian University Music Society / Société de musique des universités canadiennes, 1986
Ce document est protégé par la loi sur le droit d'auteur. L’utilisation des services d'Érudit (y compris la reproduction) est assujettie à sa politique d'utilisation que vous pouvez consulter en ligne.

https://apropos.erudit.org/fr/usagers/politique-dutilisation/ 


\title{
A SHAKESPEARE MUSIC CATALOGUE: "WHAT'S IN A NAME?"1 \\ Romeo and Juliet II, ii, 43.
}

\author{
Bryan N. S. Gooch
}

In my paper offered to a joint meeting of the Canadian Association of Music Libraries and the Canadian University Music Society on 31 May 1983,2 when the Learned Societies met at the University of British Columbia, I commented on the background to the Shakespeare Music project and explained something about the rather long route by which David Thatcher, my research colleague, and I came to the present task. I also outlined the parameters of the current project and reported briefly on our progress during our first eleven months of operation. It seems to me practical at this point to review certain details and then to move to a discussion of our methodology and results to date in order to outline for you what we have done and what we expect to achieve by our completion date in 1988; that process, at least, will explain to you "What's in [our] name".

Let me begin by noting that my colleague and I came to work on the preparation of the Shakespeare Music Catalogue after a decade of experience in literary/musical bibliography. Beginning in 1972 with a study of music connected with the late Victorians and modern British

1 An invited paper presented to the joint meeting of the Canadian Association of Music Libraries and the Canadian University Music Society, University of Montreal, 1 June 1985.

2 Canadian Association of Music Libraries Newsletter/Association canadienne des bibliotheques musicales Nouvelles, 13(1): 14-17, (March/mars 1984). 
writers, we moved to the early and mid-Victorians, and then to the British Romantics, taking into account the music produced from the authors' period to the present; catalogues of musical settings (and music influenced by the literature) in these three areas appeared sequentially, all of them published in New York and London by Garland Publishing Inc., in 1976, 1979, and 1982. All of the work was done not only because we were fascinated by the material but because we were entirely convinced that it needed to be done and that user-friendly reference works aiming at comprehensiveness in this field would be valuable to literary scholars, to musicologists, to producers of radio and television programmes, to performers, and, indeed, to anyone interested in the relationship of literature and music. Such works not only make easily available information about specific compositions, with all the appropriate manuscript and/or publication details and vocal and instrumental specifications, but facilitate, for instance, the tracing of composers' interest in a particular author, work, or set of lines and the further tracking of such interest according to, say, country and/or time period - such studies providing illumination with respect to the reception of styles and ideas. They also invite, for example, comparative literary/musical stylistic considerations, as well as examinations of two or more treatments of the same text. We have been committed, then, to the production of those bibliographic tools which would not only assist in solving the more immediate production-related problems but which would also make possible a good deal of rewarding critical work and which would serve, in their own way, as data bases for bibliographic researchers in the future.

As I noted in other papers, we had no intention when we began our first joint book of doing a second or a third, but here we are, now working on a fourth project. Certainly, we might have continued our retrospective progress and looked at, say, music connected with Restoration and eighteenth century literature - and that is an area which must be covered at some time, as must the treatment and influence on music of Elizabethan, Jacobean, Caroline, and Commonwealth material. However, no other English writer has such international currency as 
Shakespeare, and we were satisfied not only that a full coverage of Shakespeare music was necessary and would be helpful to a wide range of users (in literature, music, and theatre) but that the kind of searching involved would solve a number of difficulties (e.g., with respect to the history of music publishing, material locations, and search patterns) which would inevitably arise in the course of any study of music connected with British literature written between, say, 1600 and the time of the earliest writers listed in our book on the Romantics.

Our province includes all music, in print or in manuscript, associated in any way with Shakespeare or with his name. Thus, we have to cast a wide net and look not only for settings of Shakespearean texts but for incidental music, music bearing Shakespearean titles and epigraphs, commemorative pieces, and so on. Here the network of contacts and the research experience of our previous books come into play, for we have been able to build on what we have done so far; certainly, it is fair to say that without that experience the present project would have been at best enormously difficult to plan, let alone execute.

What we will have, when we finish, if we stay with our present single column format, is a set of five volumes. The first three will contain the catalogue proper, organised by play, poem, and other works and subdivided as follows: a) Shakespeare in Performance: Incidental Music; b) Shakespeare in Performance: Opera and Related Works; c) NonTheatrical Instrumental Music; d) Non-Theatrical Vocal Music; e) Miscellaneous Works, subdivided into categories a) to d); f) Obliquely Related Works, subdivided into categories a) to d); and g) NonShakespearean Works, subdivided into categories a) to d), a section in which we will clear up cases of misattribution. We attempt to provide, as applicable and available, the following details for each entry: a) composer's (or arranger's) name; b) title/opus number; c) MS date and location; d) title of collection/opus number/MS date and location; e) publication details (city, publisher, date, and additional information as appropriate); f) form of the work; g) vocal specifications; h) instrumental specifications; i) name(s) of librettist(s) and/or translator(s); 
j) first performance details; k) additional information about the work; l) cross reference key; and $\mathrm{m}$ ) location of printed copy (we try to include one North American and one European location). We will also provide a complete list of musical cues for each play. Each entry in the first three volumes will be numbered in sequence, making possible the use of internal cross references as well as access to the main file by composer, first line, or title; these cross references will appear in the fourth volume, along with a selected list of anthologies of Shakespeare music (the contents of each will be itemized); volume five will offer a selected and annotated bibliography of books, articles, and reviews of Shakespeare music; items will be arranged along the following lines (though several of our section headings are still tentative): a) Music in Shakespeare's Theatre; b) Shakespeare's Knowledge and Use of Music; c) Shakespeare and the Musical Arts; d) Previous Lists, Catalogues, etc., of Shakespeare Music; e) Commentaries Concerning Two or More Works; and f) Commentaries Concerning Individual Works. A numerically keyed index of composers will be included. The provision of this fifth volume means that the user can immediately identify critical material germane to some of the items in volumes one to three; however, volume five can also be used independently.

We have three main methods of securing information. First, there are the necessary, exhaustive, and sometimes potentially exhausting research trips to major repositories where material must be examined on site; given that we try to see as many scores as possible and that we cannot rely on existing catalogues because they are often insufficiently detailed for our purposes and because we do not wish to perpetuate errors - even seemingly minor ones - members of our team have to tap in person the resources of such institutions as the British Library, the Bodleian Library, the Deutsches Staatsbibiothek, the Zentralbibliothek (Zurich), the Library of Congress (and Copyright Office), the Folger Shakespeare Library, etc. Bear in mind, too, that we have to ascertain precisely which lines of Shakespeare have been set 
and determine whether the text has been altered or abbreviated in any way. It would be singularly unhelpful not to offer such information to a producer or director who might otherwise waste time and money securing a copy of a score only to find that it would not work in his production; he has to $\mathrm{kncw}$ whether lines have been telescoped or, as in the rather classic case of Lovatt's "The Pedlar's Song" (which draws its text from Act IV, scene iv of The Winter's Tale), reversed; Lovatt, in fact, begins with 11. 315-323 "Will you buy any tape"), moves to 11 . 228-230 ("Come buy"), and finishes with 11. 218-225 ("Lawn as white as driven snow"). Moreover, existing catalogues simply do not yield all the Shakespeare material contained in the collections; not only do composers select their own titles on occasion, but they resort - possibly in moments of fatigue - to bland collection titles like Three Lyrics, so that the tormented bibliographer must examine the copy. There are no short cuts and there can be no compromises. Even now, as more library catalogues are going on-line, we are still faced with some limitations with respect to search-fields, and while accessibility from a variety of angles will become the thrust of the technical developments in due course, we will probably have to bear with current frustrations for some years. And here I must add a plea to all my colleagues: I urge you to lend your wholehearted support not only to vigorous acquisition programmes but also to the cataloguing and technical services of your libraries.

A second method by which we obtain information is to solicit data by mail, frequently using our questionnaire form, derived frcm ones which we have employed over the years. Here the network of contacts, to which I referred earlier, is vital. We are in touch with associations of composers, individuals, executors, librarians - indeed, a whole host of people without whose generous assistance we could not proceed with any real effectiveness. And, of course, for this project, we have added to our list of correspondents theatre companies and societies, etc. We also seek details through solicitations in journals, critical papers, periodicals such as the ACU Bulletin, and other publications. 
And the third source is, of course, that body of material which can be examined at our base in Victoria and libraries in Vancouver. Here I would count numerous reference works, records of theatrical performances, journal runs, interlibrary loans microfilms, and xerox material (whenever that is the proper and economical method).

The key to all this is the marshalling of data, no matter what the source, in a standard form - along the lines set out in the questionnaire - so that it can be formatted for input into our computer. Haphazard recording may result in the omission of critical details and waste staff time in entry preparation. Once the details are in hand, the entry is composed, given an input number, entered on our IBM 3278.3 terminal, and proofread on the screen. Data entry is done by line type; subsequent access is by input number. Proofreading of hard copy is done as we go, and correction and emendation can be accomplished at any point. (Hard copy also can be given to team members on research trips, minimizing the potential for duplicate work.) The computer sorts and stores all our data and will assign, in the last state, sequential entry numbers (and hence all cross reference numbers); numerical shifting is automatic; and volume four (the index volume) will be generated by virtue of flagging in the main file. Our mainframe is an IBM 3083, which gives us both speed and capacity, while our terminal allows us to enter accents in languages other than English. (We do transliterate Russian and Oriental languages). While it is fair to say that the computer does a great deal for us (and we have used it and grown with the technology, thanks to the efforts of our Academic Systems staff, ever since we began our research in the seventies), it also requires that we accommodate ourselves to its demands, one of which was that we had to design a complete protocol manual - with rules for format, punctuation, etc. - before we even got to the data entry stage. And that demand, like the demand for prior and careful organisation and budgeting of the project before we began, has its benefit, for it required that we think out exactly what we wanted - and that meant, in effect, what the user wanted. Working in this area and to a clear deadline involves professionalism and discipline, but that kind of rigour in no 
way diminishes the exhilaration of the search, the delight in finding pieces of the puzzle falling into place, and the enormous pleasure in coming upon many scores of superb quality. Indeed, knowing that the technical problems have been sorted out is a comfort in tackling a body of material which constantly demands assessment of research methods and monitoring of progress; the research, in great part, is original and exciting, and any attempt to describe it with a word like "compilation" would be to mistake its nature and even belittle its construction and purpose.

There is another benefit which our computerisation will allow: we will be able, at the very least, to submit marked, formatted tapes directly to our publisher, and it is entirely possible that our technology and that of our publisher will enable us to transmit data directly by machine link and that tests on our tapes can be run before we finish our work so that, upon completion, production can proceed free of the errors which could otherwise cause irritating delays. I am also delighted to be able to note that we have concluded an agreement with Oxford University Press, which will bring out our work under the Clarendon imprint.

Let me turn now to the matter of progress. As I indicated earlier, I deliver this report almost at the end of our third year (and the mid-point of our work). We have now on hand listings of well over 11,000 items for volumes one, two, and three, already a significant number if we remember that the most comprehensive catalogue in the area to date (Hartnoll, 1964) contains some 3,000 items. Our original estimate that there might be as many as 30,000 items to be documented seems now to be somewhat high, though on reflection I feel it was a reasonable extrapolation based on our previous work, and necessary in order for us to have some sense of volume lengths. However, what has emerged is that our annotations are in many cases fuller than we had anticipated, for the amount of detail we have turned up has sometimes been extensive and in every sense worthy of inclusion. In terms of volume five - the selected bibliography of critical material - we have now verified over 2,000 items for inclusion and are well on our way to a total of 
between 3,000 and 3,500 items. Certainly, the process of verifying and annotating these bibliography entries is laborious and time consuming; details must be correct, and we cannot allow the perpetuation of errors or ghosts.

As I mentioned in 1983, one of our mandates is the development of the Shakespeare Music holdings (music and critical works) in the McPherson Library of the University of Victoria, and to date we have added over 1,100 works. We were particularly fortunate this year, as well, in that Professor Charles Haywood (Professor Emeritus, CUNY) donated to the university his entire collection of books, scores, recordings, and research slips (some 20,000 files) in this area, the result of some 40 years of dedicated work in the field, and in so doing gave us free use of all his findings. We acknowledge Professor Haywood's gift with gratitude and will include an appropriate notation on our title page and in the prefaces to volumes one and five.

The distribution of musical works by play category is working out as might be expected; most have been inspired by the comedies, less by the tragedies, and still less by the history plays. Of the plays, however, Twelfth Night is the front runner, and not The Tempest, as might have been anticipated. We are also proceeding well with our location and documentation of manuscript works, although I would implore anyone aware of works which may not be in public hands or which have been written, for example, by composers who are (or were) not members of national organisations to let us have the details or advise us as to how we can get the relevant information.

Some of our discoveries along the way have been intriguing - for a variety of reasons. We would obviously include here a host of items, both in print and in manuscript, which, though undocumented in Shakespearean and, in many cases, musical sources, are eminently performable and deserve to be better known. (And here, of course, is one of the spin-off benefits not just of this catalogue but of earlier ones - the composer has his work listed in a central source with appropriate 
indicators which suggest how a copy of the work can be obtained.) But beyond these are the bibliographic finds. For instance, our team turned up in the Folger Shakespeare Library some 40 boxes of uncatalogued music; some of it we were aware of and had seen elsewhere; some of it we knew about but had been trying to locate (and even major deposit libraries, e.g., the British Library and the Bodleian, do not hold everything they apparently ought to have); and some of it we had no record of at all. The Tenbury Collection in the Bodleian yielded a number of undocumented MSS (dating from 1797 to 1800) by members of the Harmonic Society of Oxford (e.g., G. D'Arville, J. Marsh, J. Prinz, et al) and another miscellaneous MS by Gilbert Heathcote. In the Pendlebury Library at Cambridge are the uncatalogued papers and music of Edward J. Dent, including an undated MS of 11 of 12 numbers frcm his incidental music (scored for woodwind quintet) for The Merchant of Venice. And the Fitzwilliam Museum holds three hitherto undocumented MSS of none other than R.J.S. Stevens, whose work, we thought, had been rather fully explored, and among these is his whimsical response to his own well known "Sigh no more, ladies" - a glee (probably from 1788) for SSATB, a capella, with a text by Birch entitled "Sigh I must Henry." And from another source comes another gem: T. J. Walsh in Second Empire Opera: The Théatre Lirique, Paris 1851-1870 (London: John Calder Ltd. in conjunction with Riverrun Press, Inc., 1981), p. 157, includes the following comments with respect to a nineteenth century reworking of Mozart's Cosi fan tutte: "It was Mozart's score all right, or most of it, but the libretto [by Jules Barbier and Michel Carré] (who else?) was now an adaptation of Shakespeare's [Love's Labours Lost] and the whole gallimaufry was retitled Peines d'amour perdues!" Walsh mentions no composer or adaptor responsible for arranging the Mozart score to fit the new text; the adaptation was first performed at the Théâtre Lyrique, Paris, 31 March 1863, with Léon Duprez as Prince de Navarre and Constance Caroline FaureLefébvre as Princesse d'Aquitaine.

Another kind of discovery is reminiscent of finding in different locations two pieces of the same work. Columbia University holds 5 MS 
settings by Solomon Pimsleur of Shakespeare sonnets, Nos. 8, 18, 33, 106, and 116. These are titled Shakespearean sonnet cycle, are dated "1958-1959," and are designated Opus 100; they are in full score for chorus and orchestra; soprano, alto, tenor, baritone, and bass soloists are also required but may be recruited from the chorus. However, I recently turned up in the library of Washington State University (Pullman, Washington) sketches by Pimsleur for 5 more sonnets, Nos. $29,30,66,73$, and 97; not all of these are dated, but those that are bear "1958" in the composer's hand. There is no collection title. But what is fascinating is that the Washington MSS also list (p. [1]) the numbers of all 10 sonnets, the Washington group in the left column and the Columbia group in the right. We still have to compare incipits to see if the Columbia set derive any musical inspiration from the Washington, but at this stage it seems likely that Pimsleur planned two sets (or cycles), sketched the first, moved to the second and completed that, and never returned - as far as we know at the moment - to the first. We have been able to clear up a number of dating problems and matters relating to publication history and have also documented arrangements as well as original compositions. Arrangements are vital elements in our work because they reveal the extent to which some Shakespeare music entered the popular realm and, in terms of treatments for piano, for instance, brought orchestral music into the home. In this connection a study of anthologies is also important, and while it is not our function to list every anthology reprinting, the Haywood files now in our possession contain a good deal of information in this regard, and they will be available in Victoria to researchers once we finish our work.

Our project is, then, on schedule, and while a great deal of work has been done, the next three years will be very full ones for all of us. Many repositories still need to be searched and a great many files await the tracking of missing details, and that means locating copies (not always an easy process), persuading some people to respond to our enquiries, establishing further overseas contacts, and so on. There is no manual to guide us; in a sense, we have to write it, and again it is fair 
to say that to have attempted this without our prior experiences would have been, at best, a rather foolhardy and desolate process, especially since what we are doing has been regarded, in some quarters, as impossible. What also brings it within grasp now is modern technology in two areas - communications and data handling. Further, what makes it possible is the hard work of all our team - a much larger one, necessitated by the volume of material, than we have had in the past - and the confidence and financial support of the Social Sciences and Humanities Research Council of Canada and of our own university, to which institutions we gladly offer our profound appreciation. Certainly, without the Negotiated Grant from the Council and a guarantee of six years of support we could not have begun our present work nor, indeed, managed the three previous books without the research grants which we were awarded. This point generates a further series of comments. Indeed, I suggest that is is well to reflect on the number of worthwhile projects which have been undertaken in this country because of the backing of our granting agencies and to remember that it behoves the Academy to speak lucidly and strongly about the need for the continuation and, let me be plain, the necessity, even, of increasing the funding available for research in the social sciences and humanities. That is not to neglect the sciences, and it is well to recall C. P. Snow's warning that "Intellectuals, in particular literary intellectuals, are natural Luddites."3 But technical research is patently easier to support in our somewhat utilitarian world than, say, work in the humanities, and some people in the humanities seem to assume that they ought to be supported without question and/or that someone else ought to make the arguments on their behalf, given that such defense, if necessary, is probably time-wasting and almost certainly demeaning. My point here is that the defense is important and that it must be undertaken by academics, no matter how dreary we may think the process is. Our Councils have to be supported, and the individual researcher and finally

${ }^{3}$ C.P. Snow, The Two Cultures: and A Second Look (Cambridge University Press, 1969), p. 22. 
the total community will suffer if we are at odds with them. Our appeal should be to the government and to society at large: we have to explain what we do and the value of what we do, and anyone wondering about where to start this could do far worse than to remind himself about Cardinal Newman's arguments in The Idea of a University, 1959, (particularly in the sections entitled "Knowledge Its own End," "Knowledge Viewed in Relation to Learning," and "Knowledge Viewed in Relation to Professional Skill"). Certainly, there has to be a place for the provinces of learning which constitute together the "two cultures," though I am also inclined to accept Lord Snow's view that "Attempts to divide anything into two ought to be regarded with much suspicion."4 My worry at the moment is that if we do not move to strengthen our portion of the body social, the artistic realm - that which has sometimes been referred to, should we want to flatter ourselves, as its heart - we may find ourselves living in an impoverished environment, and let me observe that no great society has ever been remembered for its technical accomplishments alone. Again, none of this should be taken as a plea to diminish work in science and technology; our society needs increased effort in that direction too; further, I suspect that we will find some of our own strongest supporters among the ranks of the scientists. Let me note that these comments come from a researcher who is grateful for the opportunity to do work which he believes needs to be done in order to build further the knowledge base within his discipline so that others may get on - expeditiously - with what they too believe to be necessary, and the comments come at a time when the word "restraint" is on many lips. To exercise restraint may well be proper, but that process demands the assignment of priorities, and unless the Academy moves broadly to maintain balance in our total culture (I prefer that notion to the always uncomfortable dichotomy) we may find ourselves with a disproportion for which a later generation will, quite properly, hold us to account.

4 Ibid. 
The second part of the title of this paper - "What's in a name?", is addressed explicitly by my comments about our project; it is also addressed implicitly by what is apparent about the very nature of the research work which is multi-disciplinary and which seeks to serve, directly and indirectly, the total society, within the Academy and without. We are excited about what we have been given the opportunity to do, and for me a great part of that excitement stems not only from the attractiveness of solving bibliographic problems but from playing a part in an effort which, along with the work of others in projects related and unrelated, will assist in telling us more about who and what we are. That, finally, is the product of knowledge; without that enlightenment man dooms himself to the proverbial beer and circus routine, to a denial of that virtue and excellence which is within his capacity to attain, to a world in which the measure of man's grasp of technology is by no means sustained by his grasp of himself, and to a future in which his best effort becomes trivialised by brutishness of spirit. And that scenario everyone must make an effort to avoid. 


\section{REFERENCES}

\section{GOOCH, BRYAN N.S.}

1984: "The Shakespeare Music Catalogue," Canadian Association of Music Libraries Newsletter / Association canadienne des bibliothèques musicales Nouvelles, 13/1 (March / mars), 14-17.

GOOCH, BRYAN N.S. and DAVID S. THATCHER, eds.

1976: Musical Settings of Late Victorian and Modern British Literature: A Catalogue. New York and London: Garland Publishing Inc.

1979: Musical Settings of Early and Mid-Victorian Literature: A Catalogue. New York and London: Garland Publishing Inc.

1982: Musical Settings of British Romantic Literature: A Catalogue. 2 volumes, New York and London: Garland Publishing, Inc.

HARTNOLL, PHLLIS, ed.

1964: Shakespeare in Music. London: Macmillan, New York: St. Martins Press.

NEWMAN, JOHN HENRY

1959: The Idea of a University. Introduction by George N. Shuster. Garden City, New York: Image Books (Division of Doubleday \& Co., Inc.).

SNOW, C.P.

1969: The Two Cultures; and A Second Look. Cambridge: Cambridge University Press.

WALSH, T.J.

1981: Second Empire Opera: The Théâtre Lyrique, Paris 1851-1870. London: John Calder Ltd. in conjunction with Riverrun Press, Inc. 